\title{
Electrocardiographic criteria for interatrial block
}

\author{
Marco Marano
}

Received: 8 May 2013/Accepted: 8 May 2013/Published online: 23 May 2013

(C) Springer Science+Business Media Dordrecht 2013

\section{Editor,}

I congratulate the authors of interesting paper "Electrocardiographic P-wave characteristics in patients with end-stage renal disease: P-index and interatrial block" recently published in your journal [1]. They first reported high prevalence of interatrial block in patients undergoing dialysis. However, it should be noted that the criteria used to define the block are incorrect. In fact, in agreement with their reference number 11 [2] and with Bayes de Luna [3], partial interatrial block was defined as prolonged P-wave (greater or equal to $110 \mathrm{~ms}$ ) but not "in all leads," just in largest one. Similarly, bifid P-waves or bimodal morphology was not "in all" but "usually" or "especially" in leads I, aVL, and inferior leads. In addition, advanced or third-degree interatrial block is defined as prolonged and biphasic (+ -) P-waves not in "all 12-leads," but in leads II, III, and aVF. I think it is just a typing error.

Thank you for the hospitality.
Conflict of interest The author declares no conflict of interest.

\section{References}

1. Solak Y et al (2013) Electrocardiographic P-wave characteristics in patients with end-stage renal disease: P-index and interatrial block. Int Urol Nephrol 45:511-517

2. Ariyarajah V et al (2005) Interatrial block: pandemic prevalence, significance, and diagnosis. Chest 128(2):970-975

3. Bayes de Luna A (2012) Interatrial blocks. A separate entity from left atrial enlargement: a consensus report. J Electrocardiol 45:445-451

M. Marano ( $\square)$

Emodialisi CI.MA.SA. Gruppo Casa di Cura Maria Rosaria,

Pompei, Italy

e-mail: marco.marano@live.it 